Journal of the European Mosquito Control Association, 2021; 39(1): 1-2

\title{
Taking JEMCA to the world stage
}

\section{EDITORIAL}

2021 is a landmark year for the Journal of the European Mosquito Control Association (JEMCA)! In the last 12 months we moved from self-publishing to the professional publisher Wageningen Academic Publishers (WAP). This is intended to gain efficiency in the submission, reviewing and publishing process, and also to get better indexed and evaluated, the final aim being to link authors and readers, promoting dissemination of science, improving knowledge on vectors and addressing related challenges.

The JEMCA story started in 1998, when Prof. Christine Dahl, Dr Clement Ramsdale and Prof. Keith Snow launched the publication of the European Mosquito Bulletin (EMB). Their first words were 'Welcome to the first issue of the European Mosquito Bulletin, a new publication designed to encourage the exchange of information and views on all aspects of the study of European mosquitoes' (Dahl, 1998). I remember well that period, when journals were not yet available online, since I was waiting for the printed issues to read news about European mosquitoes.

Two years later, the European Mosquito Control Association (EMCA) was created with, among others, the common aim to disseminate state-of-the-art knowledge about vectors, and soundly the EMB became the official journal of the EMCA. In 2001 both titles EMB and JEMCA became in use, and from 2013 EMB was not longer used. That year, major changes were performed, when moving from printed to online issues, changing the outline, and becoming webhosted by the British National History Museum (Journal of the European Mosquito Control Association (myspecies. info)). From there and until 2020, the JEMCA was handled by an editorial team, comprising 4 co-editors, namely $\mathrm{Dr}$ Paulo Almeida, Dr Helge Kampen, Dr Jolyon Medlock, and myself, assisted by some other editorial board members. In addition, Alex Vaux was kindly producing the proofs and maintaining the website. It's my duty to deeply thank the BNHM and all these contributors, as well as reviewers and authors, who together did permit to publish not less than 231 articles over this 23-years period.

Unfortunately during that period, the annual number of published paper has slowly decreased. Therefore a question did rise: is the JEMCA still useful and needed in a context of multiplication of online journals? That was discussed within the JEMCA Editorial Board and the EMCA Board and we came to the assessment that gaps are still existing in the scientific journals landscape when addressing surveillance and control of vectors and that the JEMCA can fill these gaps, but also that a lack of visibility, indexing and impact factor is reigning article submissions in. At the same period, WAP did approach us, proposing their support to publish the JEMCA. This was an excellent opportunity and, with the agreement and encouragement of the EMCA membership obtained at our Annual General Meeting 2020, we make this collaboration concrete.

As an outcome, the JEMCA is now published and hosted by WAP, with a modern submission process, an improved outline, and a renewed editorial team. As editor-in-chief, my sincere acknowledgments go to Mike Jacobs and Renate Smallegange (WAP), to the EMCA Board, to my co-editors Dr Helge Kampen and Dr Jolyon Medlock, to the other members who already accepted to join the Editorial Board, and to the reviewers and authors of the four first articles herein, for the quality of the already reached achievements. 
A supplementary change is the application of publication fees. While earlier all publication efforts were free of charges, the new process implies expenses that are proposed to be shared between authors and the EMCA. Some sponsoring (there is place for a few advertisements on our webpages) may support the EMCA to keep publication fees as low as possible, and we thank our first sponsor AVIA-GIS who already engaged to support the JEMCA. Let me stress that sponsors have of course no influence on the JEMCA's articles content.

This said, I'm eager to encourage authors to submit articles to the JEMCA. With this renewal, we aim at providing a forum for information on vector and pest arthropods of public and animal health importance. Beside mosquitoes these comprise also blackflies, phlebotomine sand flies, Culicoides biting midges, other biting flies, and ticks. Articles may address these vectors and pest species for Europe and its associate territories, but also for any other region. They may deal with, but are not restricted to, aspects of control methods and tools, identification and taxonomy, distribution, ecology and field studies, reports on surveillance and monitoring, as well as applied research on biology and pathogen transmission.

The JEMCA is already indexed in Zoological Record by Web of Science, but we are aiming to also become indexed in a short-term in other literature data bases such as Medline, and to get evaluated for an impact factor in a mid-term. To achieve that, we need to reach a minimum of 20 papers per year. Therefore I strongly encourage any author but in particular those who contributed to the recent EMCA 2021 international conference (EMCA, 2021) to submit a manuscript. Besides research results, we are happy to receive e.g. surveillance reports, description of surveillance and control tools, analysis and validation of morphological diagnostic characters, discussion on viewpoints, etc. Also special issues may be published under the lead of guest editors, and any theme suggestion is welcome.

In summary, the newly established cooperation with WAP is a very exciting development for the JEMCA, and I'm convinced it will be most beneficial to the growing success of our international, online journal, given that authors will support this challenge by submitting manuscripts. Hoping you enjoy this first issue, I look forward to new manuscripts!

\section{Dr Francis Schaffner}

Editor-in-Chief

\section{References}

Dahl, C., 1998. Winged Victory? European Mosquito Bulletin/Journal of the European Mosquito Control Association 1: 1-2.

European Mosquito Control Association, 2021. $\mathrm{X}^{\text {th }}$ International EMCA Conference - new insights into mosquito and blackfly control. Journal of the European Mosquito Control Association 39(Supplement 1): S1-S72. https://doi.org/10.52004/jemca2021.s1 